OPEN ACCESS

Edited by:

Nobuhito Imanaka,

Osaka University, Japan

Reviewed by:

Tomokatsu Hayakawa,

Nagoya Institute of Technology, Japan

Saburo Hosokawa,

Kyoto University, Japan

*Correspondence:

Hideki Kato

hideki.kato.e2@tohoku.ac.jp

Specialty section:

This article was submitted to

Physical Chemistry and Chemical

Physics,

a section of the journal

Frontiers in Chemistry

Received: 20 July 2018 Accepted: 18 September 2018 Published: 04 October 2018

Citation:

Kato H, Takeda Y, Kobayashi M, Kobayashi H and Kakihana M (2018)

Photoluminescence Properties of

Layered Perovskite-Type Strontium Scandium Oxyfluoride Activated With

$\mathrm{Mn}^{4+}$. Front. Chem. 6:467.

doi: 10.3389/fchem.2018.00467

\section{Photoluminescence Properties of Layered Perovskite-Type Strontium Scandium Oxyfluoride Activated With $\mathrm{Mn}^{4+}$}

\author{
Hideki Kato ${ }^{1 *}$, Yohei Takeda ${ }^{1}$, Makoto Kobayashi ${ }^{1}$, Hisayoshi Kobayashi ${ }^{2}$ and \\ Masato Kakihana ${ }^{1}$ \\ ${ }^{1}$ Institute of Multidisciplinary Research for Advanced Materials, Tohoku University, Sendai, Japan, ${ }^{2}$ Department of Chemistry \\ and Materials Technology, Graduate School of Science and Technology, Kyoto Institute of Technology, Kyoto, Japan
}

In this research, we have found that layered perovskite titanate $\mathrm{Sr}_{2} \mathrm{TiO}_{4}$ doped with $\mathrm{Mn}^{4+}$ exhibits photoluminescence even at room temperature despite no luminescence from $\mathrm{Mn}^{4+}$-doped $\mathrm{SrTiO}_{3}$ with a three-dimensional bulky perovskite structure. The relative position of $t_{2 g}$ orbital of $\mathrm{Mn}$ to the valence band is a key factor for appearance of $\mathrm{Mn}^{4+}$-emission in $\mathrm{Sr}_{2} \mathrm{TiO}_{4}: \mathrm{Mn}$. This result suggested usefulness of layered perovskite-type materials as hosts for $\mathrm{Mn}^{4+}$-activated phosphors than the bulky perovskite-type materials. Our investigation into photoluminescence of $\mathrm{Mn}^{4+}$-doped layered perovskite compounds has revealed that strontium scandium oxyfluoride $\mathrm{Sr}_{2} \mathrm{ScO}_{3} \mathrm{~F}$ activated with $\mathrm{Mn}^{4+}$ exhibits $\mathrm{Mn}^{4+}$-emission with a peak at $697 \mathrm{~nm}$ under excitation at $300-600 \mathrm{~nm}$ and its emission intensity is much stronger than that of $\mathrm{Sr}_{2} \mathrm{TiO}_{4}: \mathrm{Mn}$. The internal and external quantum yields of $\mathrm{Sr}_{2} \mathrm{ScO}_{3} \mathrm{~F}: \mathrm{Mn}$ were determined to be 50.5 and $43.5 \%$ under excitation at $345 \mathrm{~nm}$, respectively.

Keywords: photoluminescence, scandium oxyfluoride, layered perovskite, tetravalent manganese, red emission

\section{INTRODUCTION}

White light emitting diodes (W-LEDs) based on blue-LEDs are widely spreading to various fields as highly efficient solid lightings (Lin et al., 2016; Adachi, 2018; Wang et al., 2018). Artificial white light is basically obtained by combination of blue and yellow light emitted from a blue-LED chip and a yellow-emitting phosphor $\mathrm{Y}_{3} \mathrm{Al}_{5} \mathrm{O}_{12}$ :Ce, respectively. Such white light is inevitably cool white with high color temperature due to poor emission strength of $\mathrm{Y}_{3} \mathrm{Al}_{5} \mathrm{O}_{12}$ :Ce in red region. Efficient redemitting phosphors are added to achieve artificial warm white light by tuning color temperature. Nitride phosphors activated with $\mathrm{Eu}^{2+}$ such as $(\mathrm{Sr}, \mathrm{Ca}) \mathrm{AlSiN}_{3}: \mathrm{Eu}^{2+}$ and $M_{2} \mathrm{Si}_{5} \mathrm{~N}_{8}: \mathrm{Eu}^{2+}(M=$ $\mathrm{Ca}, \mathrm{Sr}$, and $\mathrm{Ba}$ ) are extensively studied and commercially used as the red-emitting phosphors ( $\mathrm{Li}$ et al., 2006, 2009; Uheda et al., 2006; Watanabe and Kijima, 2009; Tsai et al., 2015; Wang et al., 2018). However, requirements of high temperature and high pressure in synthesis of nitrides are drawbacks of nitride phosphors rising the costs. Therefore, development of alternative yellowto red-emitting phosphors activated with $\mathrm{Eu}^{2+}$, which can be synthesized milder conditions in comparison with nitrides, is also conducted for oxides, phosphates, and oxyhalides (Toda et al., 2006; Daicho et al., 2012, 2018; Kim et al., 2013; Sato et al., 2014; Wen et al., 2016). Besides, phosphors activated with $\mathrm{Mn}^{4+}$ have been recently paid attention due to capability of red emission 
using wide variety of host materials (Srivastava and Beers, 1996; Seki et al., 2013; Ye et al., 2013; Sasaki et al., 2014; Wang et al., 2014; Takeda et al., 2015, 2017; Zhou et al., 2016; Cai et al., 2017; Wu et al., 2017; Xi et al., 2017; Zhang et al., 2017; Adachi, 2018; Jansen et al., 2018). Octahedral 6fold coordination sites are preferred for substitution of $\mathrm{Mn}^{4+}$ ions. Fluorides and aluminates are paid much attention as hosts of $\mathrm{Mn}^{4+}$-activated phosphors from the viewpoints of their insulating nature and octahedral sites. Besides, titanates having semiconducting nature are also available for hosts of $\mathrm{Mn}^{4+}$. activated phosphors (Srivastava and Beers, 1996; Seki et al., 2013; Ye et al., 2013; Sasaki et al., 2014; Takeda et al., 2015; Zhang et al., 2017). We have recently reported that double perovskite-type titanates $\mathrm{La}_{2} \mathrm{MTiO}_{6}(\mathrm{M}: \mathrm{Mg}$ and $\mathrm{Zn}$ ) are available as host materials of $\mathrm{Mn}^{4+}$-activated phosphors although a representative perovskite-type titanate $\mathrm{SrTiO}_{3}$ doped with $\mathrm{Mn}^{4+}$ could not show any luminescence at room temperature due to significant thermal quenching at low temperature, $\sim 100 \mathrm{~K}$ (Takeda et al., 2015). Low temperature photoluminescence measurements and theoretical band structure calculations have revealed the importance of relative position of $\mathrm{Mn} \mathrm{3d}$ orbitals to valence and conduction bands of host materials in order to avoid electron transfer from the valence band to empty $t_{2 g}$ orbital of $\mathrm{Mn}$ and photoionization. The knowledge obtained from the previous researches encourages us to expand the research target for $\mathrm{Mn}^{4+}$-activated phosphors to $\mathrm{Sr}_{2} \mathrm{TiO}_{4}$ possessing a $\mathrm{K}_{2} \mathrm{MgF}_{4}$ type layered perovskite structure. Both $\mathrm{SrTiO}_{3}$ and $\mathrm{Sr}_{2} \mathrm{TiO}_{4}$ are members in a perovskite family composed of the same constituent elements. $\mathrm{SrTiO}_{3}$ of the representative perovskite-type compound is composed of $\mathrm{TiO}_{6}$ octahedra sharing corners infinitely, building threedimensional bulky structure, while $\mathrm{Sr}_{2} \mathrm{TiO}_{4}$ has layers of the two-dimensional perovskite slab with a single $\mathrm{TiO}_{6}$ thickness separated by $\mathrm{SrO}$ layers as depicted in Figure 1. The decreases in structural dimension cause widening band gaps (ReyesLillo et al., 2016), which is thought to be a positive factor to suppress the electron transfer and/or the photoionization. Therefore, it is expected that comparison photoluminescence properties between $\mathrm{SrTiO}_{3}: \mathrm{Mn}$ and $\mathrm{Sr}_{2} \mathrm{TiO}_{4}: \mathrm{Mn}$ gives important information to understand the relationship between structural dimension and photoluminescence properties with $\mathrm{Mn}^{4+}$ activation.

In this research, we investigated photoluminescence properties of $\mathrm{Mn}^{4+}$-activated layered perovskite compounds. The differences in photoluminescence properties especially thermal quenching properties between $\mathrm{SrTiO}_{3}: \mathrm{Mn}$ and $\mathrm{Sr}_{2} \mathrm{TiO}_{4}: \mathrm{Mn}$ are discussed from features in crystal structures. In addition, we also investigated into photoluminescence properties of $\mathrm{Sr}_{2} \mathrm{ScO}_{3} \mathrm{~F}$ :Mn possessing the $\mathrm{K}_{2} \mathrm{MgF}_{4}$ type structure as well as $\mathrm{Sr}_{2} \mathrm{TiO}_{4}: \mathrm{Mn}$.

\section{EXPERIMENTS}

\section{Sample Preparation}

All powder samples were synthesized by a solid state reaction method using $\mathrm{SrCO}_{3}$ (Kanto, 99.9\%), $\mathrm{SrF}_{2}$ (Wako, 99.5\%), rutile type $\mathrm{TiO}_{2}$ (Kojundo Chemical, 99.9\%), $\mathrm{Sc}_{2} \mathrm{O}_{3}$ (Shin-Etsu

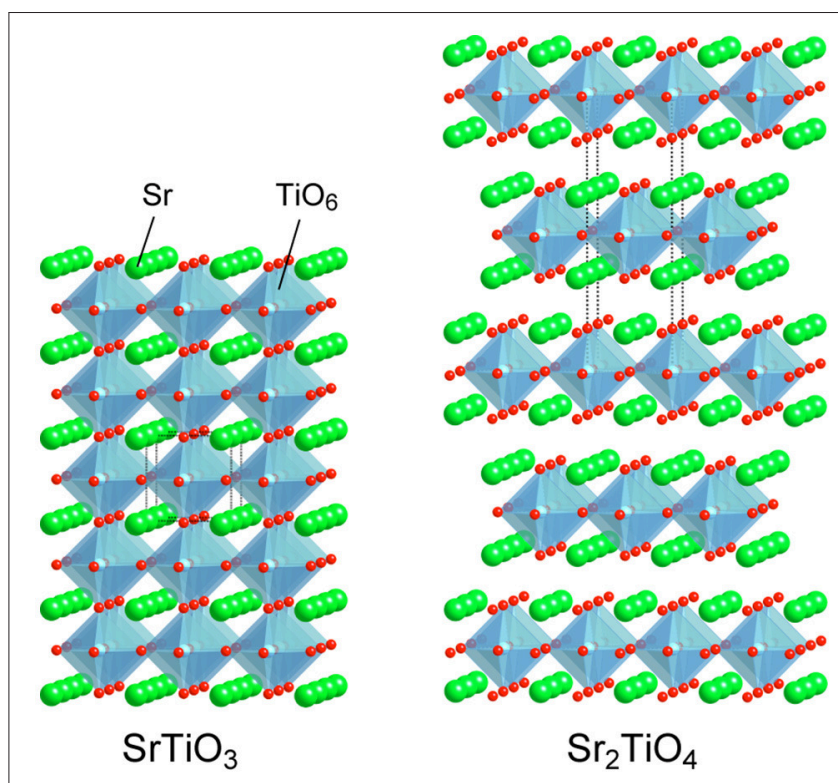

FIGURE 1 | Crystal structures of $\mathrm{SrTiO}_{3}$ and $\mathrm{Sr}_{2} \mathrm{TiO}_{4}$.

Chemical, 99.99\%), and $\mathrm{Mn}\left(\mathrm{NO}_{3}\right)_{2} 6 \mathrm{H}_{2} \mathrm{O}$ (Wako, 98.0\%) as raw materials. The stoichiometric mixtures of the raw materials were calcined at $1473 \mathrm{~K}$ for $5 \mathrm{~h}$ in air using alumina crucibles. Where, concentration of Mn substitution was fixed at 0.2 atom\% to $\mathrm{Ti}$ or Sc. Non-doped samples were also synthesized by the same manner.

\section{Characterization of Samples}

Crystal phases of obtained samples were confirmed by powder $\mathrm{X}$-ray diffraction (XRD) technique (Bruker, D2 Phaser). Photoluminescence measurements were performed using fluorescence spectrometers (Hitachi; F-4500 and Jasco; FP6500). Photoluminescence spectra were also taken at low temperature $(80-300 \mathrm{~K}$ with a step of $20 \mathrm{~K}$ ) using a cryostat (Janis; VPF-475) under vacuum. Diffuse reflectance spectra of non-doped samples were taken by an absorption spectrometer equipping an integration sphere (Shimadzu; UV-3100). The band gaps of the non-doped samples with indirect transition were determined from $(\alpha h v)^{1 / 2}-h v$ plot, where $\alpha, h$, and $v$ represent Kubelka-Munk function, Planck constant, and frequency, respectively.

\section{Band Structure Calculation}

The band structures were calculated by the plane wave based density functional theory (DFT) using CASTEP program (Payne et al., 1992; Milman et al., 2000). The Perdew-Burke-Ernzerhof (PBE) functional was used together with the ultrasoft-core potentials (Vanderbilt, 1991; Perdew et al., 1996, 1997). The cutoff energies were set to $300 \mathrm{eV}$. The electron configurations of the atoms were O: $2 s^{2} 2 p^{4}, F: 2 s^{2} 2 p^{5}$, Sc: $3 s^{2} 3 p^{6} 3 d^{1} 4 s^{2}$, Ti: $3 s^{2} 3 p^{6} 3 d^{2} 4 s^{2}, M n: 3 d^{5} 4 s^{2}$, and Sr: $4 s^{2} 4 p^{6} 5 s^{2}$. Super cells of $\mathrm{Sr}_{16} \mathrm{Ti}_{7} \mathrm{MnO}_{32}$ and $\mathrm{Sr}_{16} \mathrm{Sc}_{7} \mathrm{MnO}_{25} \mathrm{~F}_{7}$ were employed for models of $\mathrm{Sr}_{2} \mathrm{TiO}_{4}: \mathrm{Mn}$ and $\mathrm{Sr}_{2} \mathrm{ScO}_{3} \mathrm{~F}: \mathrm{Mn}$, respectively. Where, one $\mathrm{F}$ atom was also replaced with an $\mathrm{O}$ atom accompanied by the 


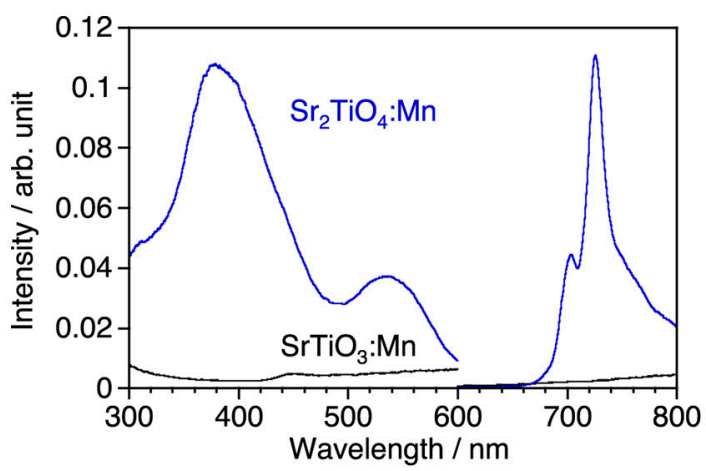

FIGURE 2 | Luminescence spectra of $\mathrm{SrTiO}_{3}: \mathrm{Mn}$ and $\mathrm{Sr}_{2} \mathrm{TiO}_{4}: \mathrm{Mn}$ and corresponding excitation spectra at room temperature. Excitation and monitored wavelengths were 380 and $725 \mathrm{~nm}$, respectively.

substitution of $\mathrm{Mn}$ for Sc to maintain the charge balance in the $\mathrm{Sr}_{2} \mathrm{ScO}_{3} \mathrm{~F}: \mathrm{Mn}$ system. From the experimental finding, the local electronic structure for the substituted $\mathrm{Mn}$ atom is known to be a $4+$ cation, and the $\mathrm{Mn}$ ion is in the quintet state. Geometry optimization was carried out with respect to all atomic coordinates.

\section{RESULTS AND DISCUSSION}

\section{Luminescence of $\mathrm{Sr}_{2} \mathrm{TiO}_{4}: \mathrm{Mn}$}

Figure 2 shows photoluminescence spectra of $\mathrm{SrTiO}_{3}: \mathrm{Mn}$ and $\mathrm{Sr}_{2} \mathrm{TiO}_{4}: \mathrm{Mn}$ with corresponding excitation spectra at room temperature. $\mathrm{Sr}_{2} \mathrm{TiO}_{4}$ :Mn showed deep-red emission with a peak at $725 \mathrm{~nm}$ attributed to ${ }^{2} \mathrm{E}_{g} \rightarrow{ }^{4} \mathrm{~A}_{2 g}$ transition of $\mathrm{Mn}^{4+}$ under excitation at $300-580 \mathrm{~nm}$. Although the emission intensity is not high, this is an interesting result taking into consideration of the fact that $\mathrm{SrTiO}_{3}: \mathrm{Mn}$ shows no emission at room temperature due to significant thermal quenching. Although both strontium titanates are composed of the same elements and are members of the perovskite family, a remarkable difference is present with regard to the structural dimension; $\mathrm{Sr}_{2} \mathrm{TiO}_{4}$ has a twodimensional layered structure whereas $\mathrm{SrTiO}_{3}$ has a threedimensional bulky one. Therefore, the appearance of $\mathrm{Mn}^{4+}$ emission in $\mathrm{Sr}_{2} \mathrm{TiO}_{4}: \mathrm{Mn}$ may reflect advantage of the layered perovskite structure in the band structure than bulky one. The further discussion about $\mathrm{Sr}_{2} \mathrm{TiO}_{4}: \mathrm{Mn}$ is described later.

\section{Comparison of Luminescence Properties Between $\mathrm{Sr}_{2} \mathrm{ScO}_{3} \mathrm{~F}: \mathrm{Mn}$ and $\mathrm{Sr}_{2} \mathrm{TiO}_{4}: \mathrm{Mn}$}

Although, as shown in Figure $\mathbf{3} \mathbf{A}, \mathrm{Sr}_{2} \mathrm{TiO}_{4}$ has a wider band gap $(3.46 \mathrm{eV})$ than $\mathrm{SrTiO}_{3}(3.21 \mathrm{eV})$ as reported in literature (ReyesLillo et al., 2016), other layered perovskite compounds possessing wider band gaps are preferred for efficient $\mathrm{Mn}^{4+}$-emission because of less probability of the electron transfer between $\mathrm{Mn}$ $3 \mathrm{~d}$ and the valence and/or conduction band. Strontium scandium oxyfluoride $\mathrm{Sr}_{2} \mathrm{ScO}_{3} \mathrm{~F}$ with a $\mathrm{K}_{2} \mathrm{MgF}_{4}$ type structure as well as $\mathrm{Sr}_{2} \mathrm{TiO}_{4}$, which has been recently discovered (Wang et al., 2015), was thought to be a good candidate because its octahedral building unit $\mathrm{ScO}_{5} \mathrm{~F}$ based on the optically inert rare earth
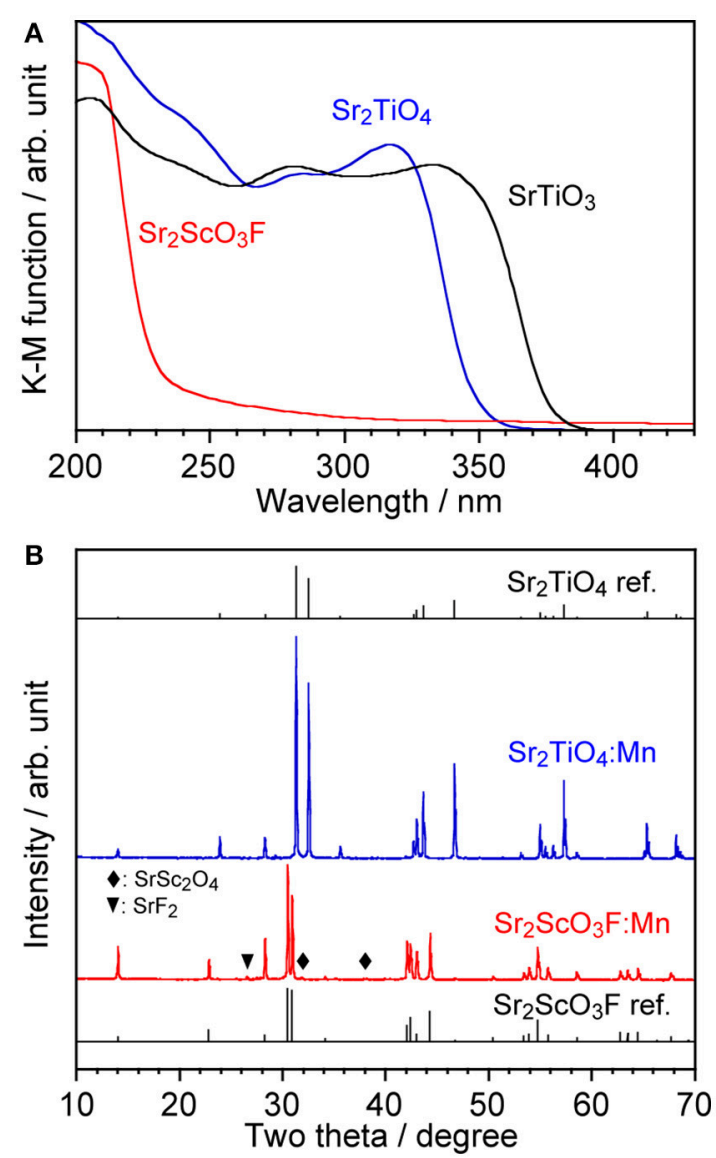

FIGURE 3 | (A) Diffuse reflectance spectra of non-doped $\mathrm{Sr}_{2} \mathrm{TiO}_{4}, \mathrm{Sr}_{2} \mathrm{ScO}_{3} \mathrm{~F}$ and $\mathrm{SrTiO}_{3}$ and (B) XRD patterns of $\mathrm{Sr}_{2} \mathrm{TiO}_{4}: \mathrm{Mn}$ and $\mathrm{Sr}_{2} \mathrm{ScO}_{3} \mathrm{~F}: \mathrm{Mn}$ with reference patterns.

element was expected to give a wider energy gap in comparison with $\mathrm{TiO}_{6}$. XRD confirmed that $\mathrm{Sr}_{2} \mathrm{ScO}_{3} \mathrm{~F}$ :Mn was obtained as the almost pure phase of $\mathrm{Sr}_{2} \mathrm{ScO}_{3} \mathrm{~F}$ although it contained tiny amounts of $\mathrm{SrF}_{2}$ and $\mathrm{SrSc}_{2} \mathrm{O}_{4}$ as impurities whereas $\mathrm{Sr}_{2} \mathrm{TiO}_{4}: \mathrm{Mn}$ was obtained as a pure phase without any impurities (Figure 3B). Relative intensities of diffraction peaks of $\mathrm{Sr}_{2} \mathrm{ScO}_{3} \mathrm{~F}: \mathrm{Mn}$ at 14.1, 28.3, 43.0, and 58.5 degrees corresponding to reflections from (002), (004), (006), and (008), respectively, were remarkably strong in comparison with the standard ones due to orientation of crystals in $(00 l)$. The band gap of $\mathrm{Sr}_{2} \mathrm{ScO}_{3} \mathrm{~F}$ has been discovered to be $5.38 \mathrm{eV}$, being wider than that of $\mathrm{Sr}_{2} \mathrm{TiO}_{4}$ (Figure 3A). Figure 4 shows emission and excitation spectra of $\mathrm{Sr}_{2} \mathrm{ScO}_{3} \mathrm{~F}: \mathrm{Mn}$ and $\mathrm{Sr}_{2} \mathrm{TiO}_{4}: \mathrm{Mn}$ at room temperature. $\mathrm{Sr}_{2} \mathrm{ScO}_{3} \mathrm{~F}: \mathrm{Mn}$ showed deep-red emission owing to transition of $\mathrm{Mn}^{4+}$ giving a peak at $697 \mathrm{~nm}$. Obvious two excitation bands in $300-460 \mathrm{~nm}$ and in $480-580 \mathrm{~nm}$ are attributed to spin-allow ${ }^{4} \mathrm{~A}_{2 g} \rightarrow{ }^{4} \mathrm{~T}_{1 g}$ and ${ }^{4} \mathrm{~A}_{2 g} \rightarrow{ }^{4} \mathrm{~T}_{2 g}$ transition of $\mathrm{Mn}^{4+}$ ions, respectively, while a weak excitation band owing to spin-forbidden ${ }^{4} \mathrm{~A}_{2 g} \rightarrow{ }^{2} \mathrm{~T}_{2 g}$ transition is difficult to distinguish and it may be embedded in the tail of the ${ }^{4} \mathrm{~A}_{2 g} \rightarrow{ }^{4} \mathrm{~T}_{1 g}$ band as observed in other titanates and tantalates (Sasaki et al., 2014; Wang et al., 2014; Takeda et al., 2015 , 2017). Interestingly, the emission from $\mathrm{Sr}_{2} \mathrm{ScO}_{3} \mathrm{~F}: \mathrm{Mn}$ was 


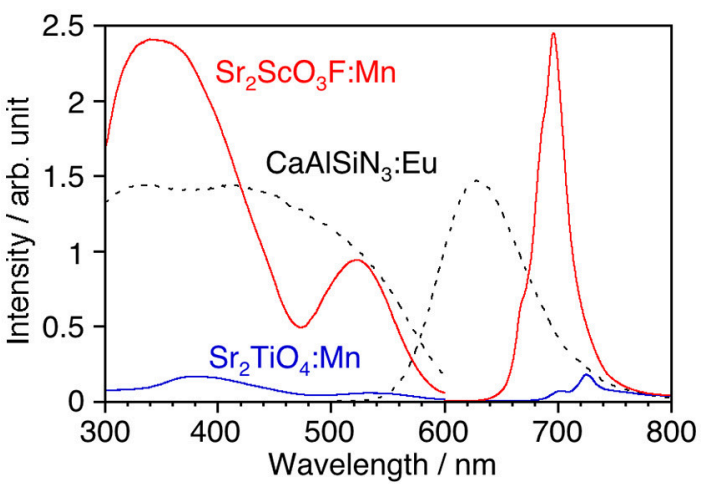

FIGURE 4 | Luminescence spectra of $\mathrm{Sr}_{2} \mathrm{TiO}_{4}: \mathrm{Mn}, \mathrm{Sr}_{2} \mathrm{ScO}_{3} \mathrm{~F}: \mathrm{Mn}$, and $\mathrm{CaAISiN}_{3}$ :Eu with corresponding excitation spectra at room temperature. Excitation and monitored wavelengths were 380 and $725 \mathrm{~nm}$ for $\mathrm{Sr}_{2} \mathrm{TiO}_{4}: \mathrm{Mn}$ 345 and $697 \mathrm{~nm}$ for $\mathrm{Sr}_{2} \mathrm{ScO}_{3} \mathrm{~F}: \mathrm{Mn}$, and 340 and $630 \mathrm{~nm}$ for $\mathrm{CaAISiN}_{3}: \mathrm{Eu}$.

much stronger than that from $\mathrm{Sr}_{2} \mathrm{TiO}_{4}: \mathrm{Mn}$; the internal and external quantum yields of $\mathrm{Sr}_{2} \mathrm{ScO}_{3} \mathrm{~F}: \mathrm{Mn}$ excited at $345 \mathrm{~nm}$ at room temperature (50.5 and $43.5 \%$ ) were much higher than those of $\mathrm{Sr}_{2} \mathrm{TiO}_{4}: \mathrm{Mn}$ excited at $380 \mathrm{~nm}$ (3.4 and 2.5\%). The $\mathrm{Mn}^{4+}$ emission from fluoride hosts consists of some very sharp lines while that from oxide hosts is broad (Zhou et al., 2016; Adachi, 2018). The emission from $\mathrm{Sr}_{2} \mathrm{ScO}_{3} \mathrm{~F}: \mathrm{Mn}$ is broad as well as $\mathrm{Mn}^{4+}$. activated oxide phosphors despite presence of the Sc-F bond. This means that influences of $\mathrm{F}$ upon the photoluminescence property of $\mathrm{Sr}_{2} \mathrm{ScO}_{3} \mathrm{~F}: \mathrm{Mn}$ are not significant. In $\mathrm{Sr}_{2} \mathrm{ScO}_{3} \mathrm{~F}: \mathrm{Mn}$, it is preferred from the charge compensation that one fluorine is replaced with one oxygen when $\mathrm{Mn}^{4+}$ is substituted for $\mathrm{Sc}^{3+}$. Such co-substitution results in the formation of $\mathrm{MnO}_{6}$ octahedra which give broad $\mathrm{Mn}^{4+}$-emission. The spectra of $\mathrm{CaSiAlN}_{3}: \mathrm{Eu}$, which is the representative red-emitting phosphor activated with $\mathrm{Eu}^{2+}$, are also shown in Figure 4. The $\mathrm{Sr}_{2} \mathrm{ScO}_{3} \mathrm{~F}: \mathrm{Mn}$ emission is sharper and stronger than the $\mathrm{CaSiAlN}_{3}$ :Eu emission however the wavelength of the $\mathrm{Sr}_{2} \mathrm{ScO}_{3} \mathrm{~F}: \mathrm{Mn}$ emission is excessively long, that is, almost the half portion of emission is located in the invisible region $(\lambda>700 \mathrm{~nm})$. $\mathrm{CaAlSiN}_{3}$ : $\mathrm{Eu}$ can be excited by blue-LEDs $(\lambda=450-470 \mathrm{~nm})$ more efficiently than $\mathrm{Sr}_{2} \mathrm{ScO}_{3} \mathrm{~F}: \mathrm{Mn}$ while $\mathrm{Sr}_{2} \mathrm{ScO}_{3} \mathrm{~F}$ :Mn can be excited by near ultraviolet LEDs $(\lambda=$ 350-400 nm) more efficiently than $\mathrm{CaAlSiN}_{3}$ :Eu.

Measurements of thermal quenching were performed at low $(80-300 \mathrm{~K})$ and high temperature ranges (298-473 K). Both samples suffered temperature quenching even in the low temperature range especially higher than $200 \mathrm{~K}$ as shown in Figures 5A-C. The maximum peak intensity decreased as measurement temperature rose while the emission of antiStokes sidebands, which were observed in regions shorter than 710 and $675 \mathrm{~nm}$ in $\mathrm{Sr}_{2} \mathrm{TiO}_{4}: \mathrm{Mn}$ and $\mathrm{Sr}_{2} \mathrm{ScO}_{3} \mathrm{~F}: \mathrm{Mn}$, respectively, was enhanced due to transition of excited electrons to upper vibration states by thermal energy (Wu et al., 2017; Adachi, 2018). It results in the non-obvious decreases in the integrated emission intensity up to $200 \mathrm{~K} . \mathrm{Sr}_{2} \mathrm{ScO}_{3} \mathrm{~F}: \mathrm{Mn}$ exhibited stronger emission than $\mathrm{Sr}_{2} \mathrm{TiO}_{4}: \mathrm{Mn}$ at all temperatures, moreover, the intensity of $\mathrm{Sr}_{2} \mathrm{TiO}_{4}: \mathrm{Mn}$ at $80 \mathrm{~K}$ was lower than that of $\mathrm{Sr}_{2} \mathrm{ScO}_{3} \mathrm{~F}: \mathrm{Mn}$ at $300 \mathrm{~K}$. Thus, $\mathrm{Sr}_{2} \mathrm{TiO}_{4}: \mathrm{Mn}$ exhibited more remarkable thermal quenching in comparison with
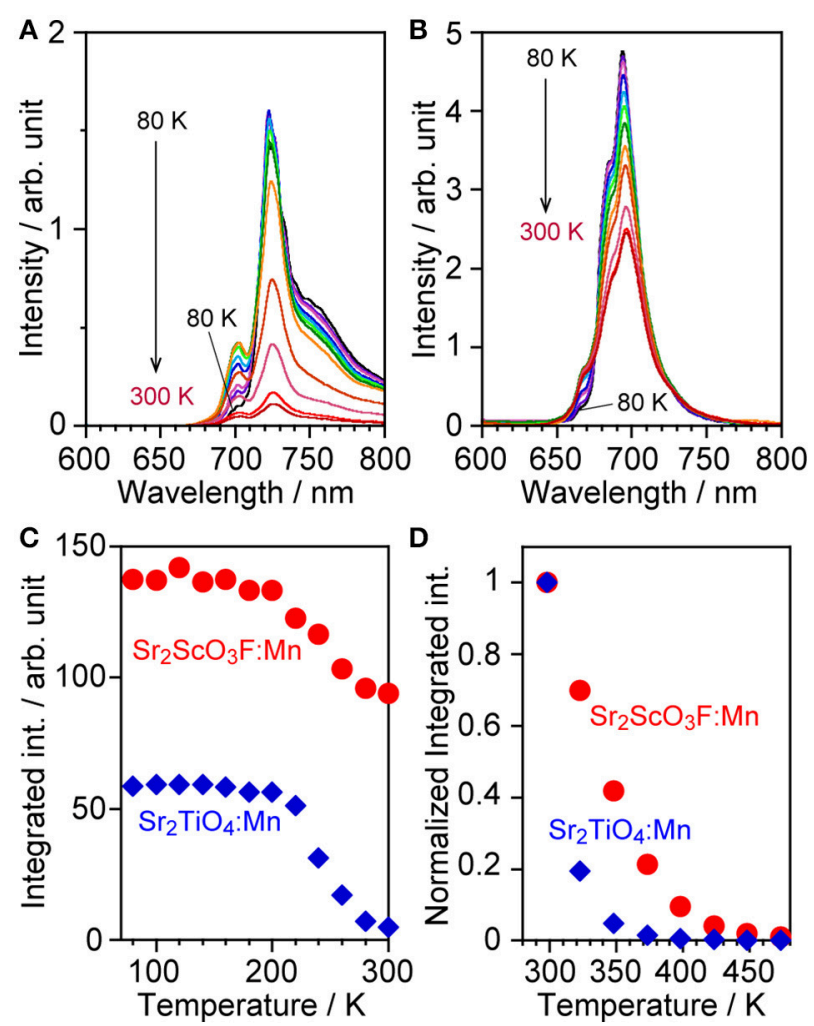

FIGURE 5 | Emission spectra of (A) $\mathrm{Sr}_{2} \mathrm{TiO}_{4}: \mathrm{Mn}$ and (B) $\mathrm{Sr}_{2} \mathrm{ScO}_{3} \mathrm{~F}: \mathrm{Mn}$ at low temperature $(80-300 \mathrm{~K})$, (C) relative integrated emission intensity of them, and (D) normalized integrated emission intensity of $\mathrm{Sr}_{2} \mathrm{TiO}_{4}: \mathrm{Mn}$ and $\mathrm{Sr}_{2} \mathrm{ScO}_{3} \mathrm{~F}: \mathrm{Mn}$ at high temperature (298-473 K). Excitation wavelengths were 380 and 340-345 nm for $\mathrm{Sr}_{2} \mathrm{TiO}_{4}: \mathrm{Mn}$ and $\mathrm{Sr}_{2} \mathrm{ScO}_{3} \mathrm{~F}: \mathrm{Mn}$, respectively.
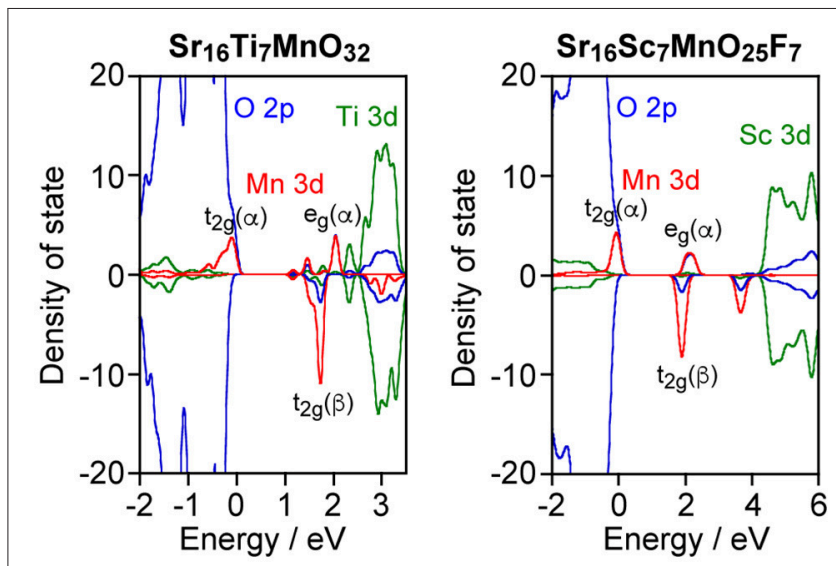

FIGURE 6 | PDOS of $\mathrm{Sr}_{16} \mathrm{Ti}_{7} \mathrm{MnO}_{32}$ and $\mathrm{Sr}_{16} \mathrm{Sc}_{7} \mathrm{MnO}_{25} \mathrm{~F}_{7}$.

$\mathrm{Sr}_{2} \mathrm{ScO}_{3} \mathrm{~F}: \mathrm{Mn}$. In the high temperature range $(298-473 \mathrm{~K})$, significant thermal quenching occurred in both samples as shown in Figure 5D, however $\mathrm{Sr}_{2} \mathrm{ScO}_{3} \mathrm{~F}: \mathrm{Mn}$ showed lesser thermal quenching than $\mathrm{Sr}_{2} \mathrm{TiO}_{4}: \mathrm{Mn}$. At $373 \mathrm{~K}, \mathrm{Sr}_{2} \mathrm{ScO}_{3} \mathrm{~F}: \mathrm{Mn}$ showed $20 \%$ of emission intensity in comparison with that at $298 \mathrm{~K}$ whereas emission from $\mathrm{Sr}_{2} \mathrm{TiO}_{4}: \mathrm{Mn}$ was completely quenched. 


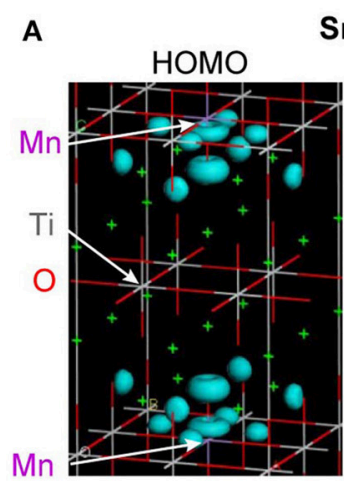

HOMO-2

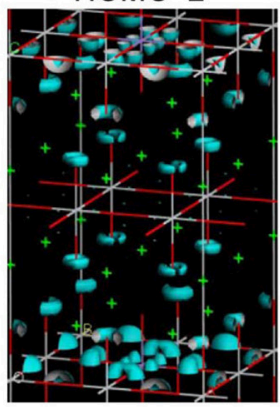

B

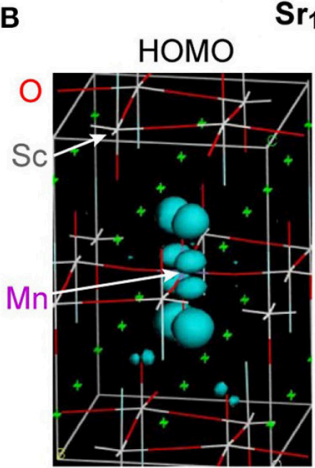

HOMO-2

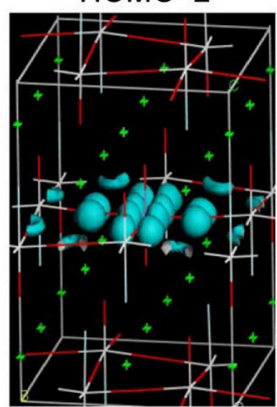

$\mathrm{Sr}_{16} \mathrm{Ti}_{7} \mathrm{MnO}_{32}$

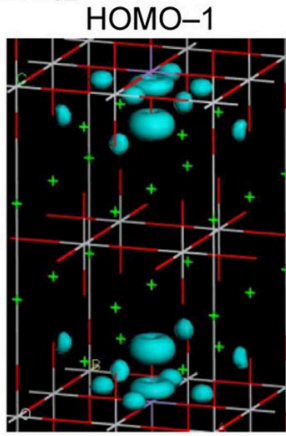

$\mathrm{HOMO}-3$

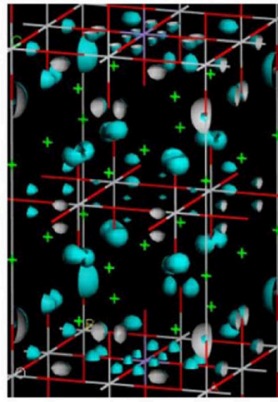

$\mathrm{r}_{16} \mathrm{Sc}_{7} \mathrm{MnO}_{25} \mathrm{~F}_{7}$

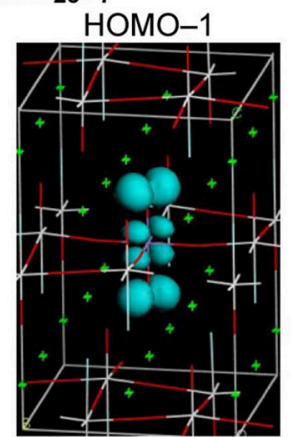

HOMO-3

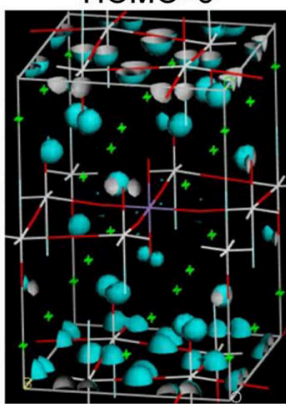

FIGURE 7 | Electron density contour maps of top four occupied orbitals for (A) $\mathrm{Sr}_{16} \mathrm{Ti}_{7} \mathrm{MnO}_{32}$ and (B) $\mathrm{Sr}_{16} \mathrm{Sc}_{7} \mathrm{MnO}_{25} \mathrm{~F}_{7}$.

\section{Band Structures of $\mathrm{Sr}_{2} \mathrm{TiO}_{4}: \mathrm{Mn}$ and $\mathrm{Sr}_{2} \mathrm{ScO}_{3} \mathrm{~F}: \mathrm{Mn}$}

As described above, $\mathrm{Sr}_{2} \mathrm{ScO}_{3} \mathrm{~F}: \mathrm{Mn}$ showed superior characteristics, that is, higher emission intensity and lesser

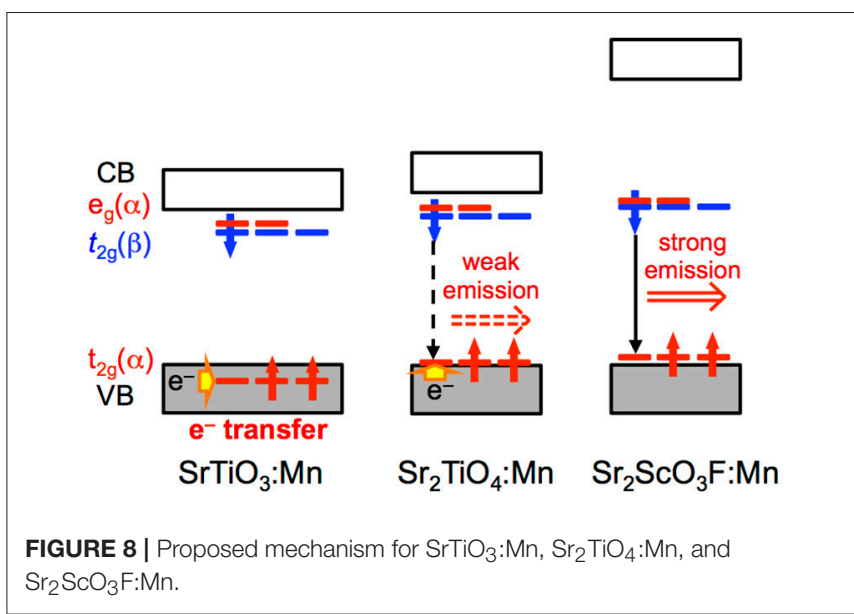

thermal quenching, to $\mathrm{Sr}_{2} \mathrm{TiO}_{4}: \mathrm{Mn}$. Relative position of $\mathrm{Mn}$ $3 \mathrm{~d}$ orbitals to the valence and conduction bands of host materials is an important factor for $\mathrm{Mn}^{4+}$-activated phosphors as we have reported previously (Takeda et al., 2015, 2017). Therefore, band structures of $\mathrm{Sr}_{2} \mathrm{TiO}_{4}: \mathrm{Mn}$ and $\mathrm{Sr}_{2} \mathrm{ScO}_{3} \mathrm{~F}: \mathrm{Mn}$ were investigated by the DFT method. Figure 6 depicts projected density of states (PDOS) near the band gap of $\mathrm{Sr}_{16} \mathrm{Ti}_{7} \mathrm{MnO}_{32}$ and $\mathrm{Sr}_{16} \mathrm{Sc}_{7} \mathrm{MnO}_{25} \mathrm{~F}_{7}$ corresponding to $\mathrm{Sr}_{2} \mathrm{TiO}_{4}: \mathrm{Mn}$ and $\mathrm{Sr}_{2} \mathrm{ScO}_{3} \mathrm{~F}: \mathrm{Mn}$. In Figure 6, positive and negative values in DOS represent DOS for up-spin $(\alpha)$ and down-spin $(\beta)$ electrons, respectively, and $0 \mathrm{eV}$ of energy represents the Fermi level. In $\mathrm{Sr}_{2} \mathrm{TiO}_{4}: \mathrm{Mn}$, the valence and conduction bands of host are composed of $\mathrm{O} 2 \mathrm{p}$ and $\mathrm{Ti} 3 \mathrm{~d}$ orbitals, respectively, like $\mathrm{SrTiO}_{3}: \mathrm{Mn}$. In PDOS of $\mathrm{Sr}_{2} \mathrm{TiO}_{4}: \mathrm{Mn}$, the $\mathrm{t}_{2 \mathrm{~g}}(\alpha)$ orbitals of Mn look to be located slightly higher position than the valence band however a tail of $t_{2 g}(\alpha)$ is embedded in the valence band. The DFT calculation reveals that $\mathrm{Sr}_{2} \mathrm{TiO}_{4}: \mathrm{Mn}$ has absolutely different feature in the relative position of $\mathrm{Mn} 3 \mathrm{~d}$ orbitals to the valence band from $\mathrm{SrTiO}_{3}: \mathrm{Mn}$, in which the $\mathrm{t}_{2 \mathrm{~g}}(\alpha)$ orbitals are deeply embedded in the valence band (Takeda et al., 2015). Although a part of $t_{2 g}(\alpha)$ orbitals is located in positive energy region, it doesn't indicate the presence of empty $\mathrm{t}_{2 \mathrm{~g}}(\alpha)$ orbitals. The total numbers of electrons calculated for both $\mathrm{Sr}_{16} \mathrm{Ti}_{7} \mathrm{MnO}_{32}$ and $\mathrm{Sr}_{16} \mathrm{Sc}_{7} \mathrm{MnO}_{25} \mathrm{~F}_{7}$ models were 443 . In the quintet state, the numbers of occupied orbitals should be 223 and 220 for $\alpha$ - and $\beta$-electrons, respectively. If the top of $t_{2 g}(\alpha)$ orbital of $\mathrm{Mn} \mathrm{3d}$ is empty, the lowest unoccupied molecular orbital for $\alpha$-electron (\#224 $\alpha$-orbital) should be Mn $3 \mathrm{~d}$ located near $0 \mathrm{eV}$. However, \#224 $\alpha$-orbital is not Mn 3d located around $0 \mathrm{eV}$ but $\mathrm{Mn} 3 \mathrm{~d}$ orbital below the conduction band [indicated as $e_{g}(\alpha)$ in Figure 6] in both models. The small portion of the occupied orbitals beyond the Fermi level observed in PDOS is due to broadening of energy widths of orbitals by the smearing treatment in the process of PDOS creation. Thus, it has been confirmed that all $\mathrm{Mn} 3 \mathrm{~d}$ orbitals around $0 \mathrm{eV}$ are occupied ones. The PDOS of $\mathrm{Sr}_{2} \mathrm{ScO}_{3} \mathrm{~F}: \mathrm{Mn}$ shows that the $t_{2 g}(\alpha)$ orbitals of $\mathrm{Mn}$ is located slightly higher position than the valence band without tailing portion at a lower energy side. The electron density contour maps for 
top four occupied molecular orbitals including the highest occupied molecular orbital (HOMO) are compared to see details of the differences between $\mathrm{Sr}_{2} \mathrm{TiO}_{4}: \mathrm{Mn}$ and $\mathrm{Sr}_{2} \mathrm{ScO}_{3} \mathrm{~F}: \mathrm{Mn}$ (Figure 7). In $\mathrm{Sr}_{2} \mathrm{ScO}_{3} \mathrm{~F}: \mathrm{Mn}$, contribution of the occupied $\mathrm{Mn}$ $3 \mathrm{~d}$ orbitals is seen only in the top three occupied orbitals (from HOMO to HOMO-2) and the forth highest occupied orbital (HOMO-3) is composed of only O $2 \mathrm{p}$ orbital. On the other hand, small contribution of the $\mathrm{Mn} 3 \mathrm{~d}$ orbital is also seen in HOMO-3 of $\mathrm{Sr}_{2} \mathrm{TiO}_{4}: \mathrm{Mn}$ although $\mathrm{Mn} 3 \mathrm{~d}$ orbitals mainly contribute to top three occupied orbitals. If hybridization between $O 2 p$ and $t_{2 g}(\alpha)$ of $M n 3 d$ is small, the occupied Mn 3d orbitals appear in only three orbitals. The appearance of $\mathrm{Mn} \mathrm{3d}$ in four orbitals in $\mathrm{Sr}_{2} \mathrm{TiO}_{4}: \mathrm{Mn}$ (from HOMO to $\mathrm{HOMO}-3$ ) indicates stronger hybridization between $\mathrm{O} 2 \mathrm{p}$ and $\mathrm{Mn} 3 \mathrm{~d}$ than $\mathrm{Sr}_{2} \mathrm{ScO}_{3} \mathrm{~F}: \mathrm{Mn}$. It is also noticed in PDOS that energy gap between $\mathrm{e}_{\mathrm{g}}(\alpha)$ of $\mathrm{Mn} 3 \mathrm{~d}$ and the bottom of conduction band is larger in $\mathrm{Sr}_{2} \mathrm{ScO}_{3} \mathrm{~F}: \mathrm{Mn}$ than $\mathrm{Sr}_{2} \mathrm{TiO}_{4}: \mathrm{Mn}$. It reflects the remarkably wider band gap of $\mathrm{Sr}_{2} \mathrm{ScO}_{3} \mathrm{~F}$ than $\mathrm{Sr}_{2} \mathrm{TiO}_{4}$.

Figure 8 illustrates proposed mechanism based on photoluminescence measurements and band structure calculations for $\mathrm{Mn}^{4+}$-activated $\mathrm{SrTiO}_{3}, \mathrm{Sr}_{2} \mathrm{TiO}_{4}$, and $\mathrm{Sr}_{2} \mathrm{ScO}_{3} \mathrm{~F}$. The most significant difference in photoluminescence property between $\mathrm{Sr}_{2} \mathrm{TiO}_{4}: \mathrm{Mn}$ and $\mathrm{SrTiO}_{3}: \mathrm{Mn}$ is the appearance of $\mathrm{Mn}^{4+}$. emission in $\mathrm{Sr}_{2} \mathrm{TiO}_{4}: \mathrm{Mn}$ at room temperature. The difference in the relative position of $\mathrm{t}_{2 \mathrm{~g}}(\alpha)$ orbitals of $\mathrm{Mn}$ between $\mathrm{SrTiO}_{3}: \mathrm{Mn}$ and $\mathrm{Sr}_{2} \mathrm{TiO}_{4}: \mathrm{Mn}$ is of importance in explanation for the appearance of $\mathrm{Mn}^{4+}$-emission in $\mathrm{Sr}_{2} \mathrm{TiO}_{4}: \mathrm{Mn}$. In $\mathrm{SrTiO}_{3}: \mathrm{Mn}$, the $t_{2 g}(\alpha)$ orbitals embedded in the valence band facilitate thermal quenching via the electron transfer from the valence band to the empty $t_{2 g}$ in the excited state ${ }^{2} E_{g}$, resulting in low quenching temperature, $\sim 100 \mathrm{~K}$ (Takeda et al., 2015). In contrast to $\mathrm{SrTiO}_{3}: \mathrm{Mn}, \mathrm{t}_{2 \mathrm{~g}}(\alpha)$ in $\mathrm{Sr}_{2} \mathrm{TiO}_{4}: \mathrm{Mn}$ is located slightly higher position than the valence band. Therefore, $\mathrm{Sr}_{2} \mathrm{TiO}_{4}: \mathrm{Mn}$ shows $\mathrm{Mn}^{4+}$-emission even at room temperature. Interaction between $\mathrm{TiO}_{6}$ octahedra may affect the relative position of $t_{2 g}(\alpha)$ orbitals of $\mathrm{Mn}$. Each $\mathrm{TiO}_{6}$ octahedron connects to six $\mathrm{TiO}_{6}$ octahedra in $\mathrm{SrTiO}_{3}$ while $\mathrm{TiO}_{6}$ connects to four $\mathrm{TiO}_{6}$ octahedra in the perovskite slab in $\mathrm{Sr}_{2} \mathrm{TiO}_{4}$ as shown in Figure 1, indicating that degree of energy delocalization is higher in three-dimensional $\mathrm{SrTiO}_{3}$ than two-dimensional $\mathrm{Sr}_{2} \mathrm{TiO}_{4}$. The smaller interaction between $\mathrm{TiO}_{6}$ octahedra may cause less interaction between $\mathrm{O} 2 \mathrm{p}$ and occupied of $\mathrm{Mn} 3 \mathrm{~d}$ orbitals, that is, $t_{2 g}(\alpha)$ orbitals. Thus, the advantage of two-dimensional layered perovskite structure for $\mathrm{Mn}^{4+}$-activated phosphors can be explained by the smaller interaction of $\mathrm{MO}_{6}$ octahedra. Such discussion can be applied to another $\mathrm{Mn}^{4+}$-activated titanate phosphor $\mathrm{La}_{2} \mathrm{MgTiO}_{6}: \mathrm{Mn}$ with a $\mathrm{B}$-site ordered double perovskite structure, which is an efficient $\mathrm{Mn}^{4+}$-activated phosphor with $58.7 \%$ of an internal quantum yield (Takeda et al., 2015). In $\mathrm{La}_{2} \mathrm{MgTiO}_{6}$, each $\mathrm{TiO}_{6}$ octahedron is surrounded by six $\mathrm{MgO}_{6}$ octahedra, meaning that $\mathrm{TiO}_{6}$ is isolated from other $\mathrm{TiO}_{6}$ octahedra even though the perovskite-type structure (Lee et al., 2000). Thus, the structure of $\mathrm{La}_{2} \mathrm{MgTiO}_{6}$ can be regarded as a quasi-zero-dimensional structure with respect to the connection between $\mathrm{TiO}_{6}$ octahedra. The less interaction of $\mathrm{TiO}_{6}$ in $\mathrm{La}_{2} \mathrm{MgTiO}_{6}: \mathrm{Mn}$ leads the larger energy gap between the valence band and $t_{2 g}(\alpha)$ of $M n$, resulting in the superior photoluminescence efficiency to $\mathrm{Sr}_{2} \mathrm{TiO}_{4}: \mathrm{Mn}$. In $\mathrm{Sr}_{2} \mathrm{ScO}_{3} \mathrm{~F}: \mathrm{Mn}$, the $t_{2 g}(\alpha)$ orbitals of Mn $3 d$ are located above the valence band with a slightly larger energy gap than $\mathrm{Sr}_{2} \mathrm{TiO}_{4}: \mathrm{Mn}$ due to the small hybridization between $\mathrm{O} 2 \mathrm{p}$ and $\mathrm{Mn} 3 \mathrm{~d}$ as described above. On the other hand, the larger energy gap between $e_{g}(\alpha)$ and the bottom of conduction band in $\mathrm{Sr}_{2} \mathrm{ScO}_{3} \mathrm{~F}: \mathrm{Mn}$ suppresses quenching via photoionization, in which an electron in $e_{g}(\alpha)$ orbitals in the excited state is transferred to the conduction band and then is relaxed without emission (Takeda et al., 2017). Thus, the two factors, the less interaction between $t_{2 g}(\alpha)$ and the valence band and the large energy gap between $\mathrm{e}_{\mathrm{g}}(\alpha)$ and the bottom of conduction band, positively affect the smaller thermal quenching in $\mathrm{Sr}_{2} \mathrm{ScO}_{3} \mathrm{~F}: \mathrm{Mn}$ than $\mathrm{Sr}_{2} \mathrm{TiO}_{4}: \mathrm{Mn}$, resulting in the stronger emission.

\section{CONCLUSIONS}

Photoluminescence properties of $\mathrm{Mn}^{4+}$-activated strontium titanates, $\mathrm{SrTiO}_{3}: \mathrm{Mn}$ with three-dimensional bulky perovskite structure and $\mathrm{Sr}_{2} \mathrm{TiO}_{4}: \mathrm{Mn}$ with two-dimensional layered perovskite structure, have been compared in this research. $\mathrm{Sr}_{2} \mathrm{TiO}_{4}$ :Mn shows $\mathrm{Mn}^{4+}$-emission even at room temperature despite no emission from $\mathrm{SrTiO}_{3}: \mathrm{Mn}$. In addition, the results in our systematic research suggest that the less interaction between $\mathrm{MO}_{6}$ octahedra of $\mathrm{B}$-site cation in the perovskite family provides positive influences in $\mathrm{Mn}^{4+}$-emission. Comparison between $\mathrm{Sr}_{2} \mathrm{TiO}_{4}: \mathrm{Mn}$ and $\mathrm{Sr}_{2} \mathrm{ScO}_{3} \mathrm{~F}: \mathrm{Mn}$ indicates that $\mathrm{ScO}_{5} \mathrm{~F}$ octahedra are preferable constituents to $\mathrm{TiO}_{6}$ ones for the $\mathrm{Mn}^{4+}$ activated phosphors. Thus, the present research demonstrates that scandium, which is one of optically inert rare earth elements, is a useful element as a major constituent for design of $\mathrm{Mn}^{4+}$-activated phosphors.

\section{AUTHOR CONTRIBUTIONS}

HidK managed all experiments and wrote the manuscript. YT performed experiments on synthesis of samples and evaluation of photoluminescence properties of them. HisK performed band structure calculations. MakK and MasK planned experiments and made discussion about the results.

\section{FUNDING}

This research was partly supported by KAKENHI Grant Numbers JP16H06438 and JP16H06439 in Scientific Research on Innovative Area Mixed Anion and JP16H02391 in Scientific Research (A) and Dynamic Alliance for Open Innovation Bridging Human, Environment and Materials in Network Joint Research Center for Materials and Devices. 


\section{REFERENCES}

Adachi, S. (2018). Photoluminescence properties of $\mathrm{Mn}^{4+}$-activated oxide phosphors for use in white-LED applications: a review. J. Lumin. 202, 263-281. doi: 10.1016/j.jlumin.2018.05.053

Cai, P., Qin, L., Chen, C., Wang, J., and Seo, H. J. (2017). Luminescence, energy transfer and optical thermometry of a novel narrow red emitting phosphor: $\mathrm{Cs}_{2} \mathrm{WO}_{2} \mathrm{~F}_{4}: \mathrm{Mn}^{4+}$. Dalton Trans. 46, 14331-14340. doi: 10.1039/C7DT02751F

Daicho, H., Iwasaki, T., Enomoto, K., Sasaki, Y., Maeno, Y., Shinomiya, Y., et al. (2012). A novel phosphor for glareless white light-emitting diodes. Nat. Commun. 3:1132. doi: $10.1038 /$ ncomms 2138

Daicho, H., Shinomiya, Y., Enomoto, K., Nakano, A., Sawa, H., Matsuishi, S., et al. (2018). A novel red-emitting $\mathrm{K}_{2} \mathrm{Ca}\left(\mathrm{PO}_{4}\right) \mathrm{F}: \mathrm{Eu}^{2+}$ phosphor with a large Stokes shift. Chem. Commun. 54, 884-887. doi: 10.1039/C7CC08202A

Jansen, T., Jüstel, T., Kirm, M., Vielhauer, S., Khaidukov, N. M., and Makhovd, V. N. (2018). Composition dependent spectral shift of $\mathrm{Mn}^{4+}$ luminescence in silicate garnet hosts $\mathrm{CaY}_{2} M_{2} \mathrm{Al}_{2} \mathrm{SiO}_{12}(M=\mathrm{Al}, \mathrm{Ga}$, Sc). J. Lumin. 198, 314-319. doi: 10.1016/j.jlumin.2018.02.054

Kim, S. W., Hasegawa, T., Ishigaki, T., Uematsu, K., Toda, K., and Sato, M. (2013). Efficient red emission of blue-light excitable new structure type $\mathrm{NaMgPO}_{4}: \mathrm{Mn}^{4+}$ phosphor. ECS Solid State Lett. 2, R49-R51. doi: $10.1149 / 2.004312$ ssl

Lee, D.-Y., Yoon, S.-J., Yeo, J.-H., Nahm, S., Paik, J. H., Whang, K.-C., et al. (2000). Crystal structure and microwave dielectric properties of $\mathrm{La}\left(\mathrm{Mg}_{1 / 2} \mathrm{Ti}_{1 / 2}\right) \mathrm{O}_{3}$ ceramics. J. Mater. Sci. Lett. 19, 131-134. doi: 10.1023/A:1006603615193

Li, H.-L., Xie, R.-J., Hirosaki, N., Takeda, T., and Zhou, G. H. (2009). Synthesis and luminescence properties of orange-red-emitting $M_{2} \mathrm{Si}_{5} \mathrm{~N}_{8}: \mathrm{Eu}^{2+}(M=\mathrm{Ca}, \mathrm{Sr}$, Ba) light-emitting diode conversion phosphors by a simple nitridation of $\mathrm{MSi}_{2}$. Int. J. Appl. Ceram. Technol. 6, 459-464. doi: 10.1111/j.1744-7402.2009.02370.x

Li, Y. Q., Steen, J. E. J., Krevel, J. W. H., Botty, G., Delsing, A. C. A., DiSalvo, F. J., et al. (2006). Luminescence properties of red-emitting $M_{2} \mathrm{Si}_{5} \mathrm{~N}_{8}$ : $\mathrm{Eu}^{2+}$ $(M=\mathrm{Ca}, \mathrm{Sr}, \mathrm{Ba})$ LED conversion phosphors. J. Alloys Compd. 417, 273-279. doi: 10.1016/j.jallcom.2005.09.041

Lin, Y. C., Karlsson, M., and Bettinelli, M. (2016). Inorganic phosphor materials for lighting. Top. Curr. Chem. 374:21. doi: 10.1007/s41061-016-0023-5

Milman, V., Winkler, B., White, J. A., Pickard, C. J., Payne, M. C., Akhmatskaya, E. V., et al. (2000). Electronic structure, properties, and phase stability of inorganic crystals: a pseudopotential plane-wave study. Int. J. Quan. Chem. 77, 895-910. doi: 10.1002/(SICI)1097-461X(2000)77:5<895::AID-QUA10>3.0.CO;2-C

Payne, M. C., Teter, M. P., Allan, D. C., Arias, T. A., and Johnnopoulos, J. D. (1992). Iterative minimization techniques for ab initio total-energy calculations: molecular dynamics and conjugate gradients. Rev. Mod. Phys. 64, 1045-1097. doi: 10.1103/RevModPhys.64.1045

Perdew, J. P., Burke, K., and Ernzerhof, M. (1996). Generalized gradient approximation made simple. Phys. Rev. Lett. 77, 3865-3868. doi: 10.1103/PhysRevLett.77.3865

Perdew, J. P., Burke, K., and Ernzerhof, M. (1997). Generalized gradient approximation made simple. Phys. Rev. Lett. 77, 3865-3868. doi: 10.1103/PhysRevLett.78.1396

Reyes-Lillo, S. E., Rangel, T., Bruneval, F., and Neaton, J. B. (2016). Effects of quantum confinement on excited state properties of $\mathrm{SrTiO}_{3}$ from ab initio many-body perturbation theory. Phys. Rev. B 94:041107. doi: 10.1103/PhysRevB.94.041107

Sasaki, T., Fukushima, J., Hayashi, Y., and Takizawa, H. (2014). Synthesis of photoluminescence properties of $\mathrm{Mn}^{4+}$-doped $\mathrm{BaMg}_{6} \mathrm{Ti}_{6} \mathrm{O}_{19}$ phosphor. Chem. Lett. 43, 1061-1063. doi: 10.1246/cl.140282

Sato, Y., Kato, H., Kobayashi, M., Masaki, T., Yoon, D.-H., and Kakihana, M. (2014). Tailoring of deep-red luminescence in $\mathrm{Ca}_{2} \mathrm{SiO}_{4}: \mathrm{Eu}^{2+}$. Angew. Chem. Int. Ed. 53, 7756-7759. doi: 10.1002/anie.201402520

Seki, K., Kamei, S., Uematsu, K., Ishigaki, T., Toda, K., and Sato, M. (2013). Enhancement of the luminescence efficiency of $\mathrm{Li}_{2} \mathrm{TiO}_{3}: \mathrm{Mn}^{4+}$ red emitting phosphor for white LEDs. J. Ceram. Process. Res. 14, s67-s70.

Srivastava, A. M., and Beers, W. W. (1996). Luminescence of $\mathrm{Mn}^{4+}$ in the distorted perovskite $\mathrm{Gd}_{2} \mathrm{MgTiO}_{6}$. J. Electrochem. Soc. 143, L203-L205. doi: $10.1149 / 1.1837087$

Takeda, Y., Kato, H., Kobayashi, M., Kobayashi, H., and Kakihana, M. (2015). Photoluminescence properties of $\mathrm{Mn}^{4+}$-activated perovskite-type titanates, $\mathrm{La}_{2} \mathrm{MTiO}_{6}: \mathrm{Mn}^{4+}(\mathrm{M}=\mathrm{Mg}$ and $\mathrm{Zn})$. Chem. Lett. 44, 1541-1543. doi: $10.1246 / \mathrm{cl} .150748$

Takeda, Y., Kato, H., Kobayashi, M., Nozawa, S., Kobayashi, H., and Kakihana, M. (2017). Photoluminescence properties of double perovskite tantalates activated with $\mathrm{Mn}^{4+}, A E_{2} \mathrm{LaTaO}_{6}: \mathrm{Mn}^{4+}(A E=\mathrm{Ca}, \mathrm{Sr}$, and Ba). J. Phys. Chem. C 121, 18837-18844. doi: 10.1021/acs.jpcc.7b06280

Toda, K., Kawakami, Y., Kousaka, S., Ito, Y., Komeno, A., Uematsu, K., et al. (2006). New silicate phosphors for a white LED. IEICE Trans. Electoron. E89-C, $1406-1412$.

Tsai, Y. T., Chiang, C. Y., Zhou, W., Lee, J. F., Sheu, H. S., and Liu, R. S. (2015). Structural ordering and charge variation induced by cation substitution in (Sr,Ca)AlSiN 3 :Eu phosphor. J. Am. Chem. Soc. 137, 8936-8939. doi: 10.1021 /jacs.5b06080

Uheda, K., Hirosaki, N., Yamamoto, Y., Naito, A., Nakajima, T., and Yamamoto, H. (2006). Luminescence properties of a red phosphor, CaAlSiN $3: \mathrm{Eu}^{2+}$, for white light-emitting diodes, Electrochem. Solid State Lett. 9, H22-H25. doi: $10.1149 / 1.2173192$

Vanderbilt, D. (1991). Implementation of ultrasoft pseudopotentials in ab initio molecular dynamics. Phys. Rev. B 43, 6796-6799. doi: 10.1103/PhysRevB.43.6796

Wang, L., Xie, R. J., Suehiro, T., Takeda, T., and Hirosaki, N. (2018). Downconversion nitride materials for solid state lighting: recent advances and perspectives. Chem. Rev. 118, 1951-2009. doi: 10.1021/acs.chemrev.7b00284

Wang, L., Yuan, L., Xu, Y., Zhou, R., Qu, B., Ding, N., et al. (2014). Luminescent properties of $\mathrm{LaLiTaO}_{6}: \mathrm{Mn}^{4+}$ and its application as red emission LEDs phosphor. Appl. Phys. A: Mater. Sci. Process. 117, 1777-1783. doi: $10.1007 / \mathrm{s} 00339-014-8827-\mathrm{z}$

Wang, Y., Tang, K., Zhu, B., Wang, D., Hao, Q., and Wang, Y. (2015). Synthesis and structure of a new layered oxyfluoride $\mathrm{Sr}_{2} \mathrm{ScO}_{3} \mathrm{~F}$ with photocatalytic property. Mater. Res. Bull. 65, 42-46. doi: 10.1016/j.materresbull.2015.01.042

Watanabe, H., and Kijima, N. (2009). Crystal structure and luminescence properties of $\mathrm{Sr}_{x} \mathrm{Ca}_{1--x} \mathrm{AlSiN}_{3}: \mathrm{Eu}^{2+}$ mixed nitride phosphors. J. Alloy Compd. 475, 434-439. doi: 10.1016/j.jallcom.2008.07.054

Wen, D., Kuwahara, H., Kato, H., Kobayashi, M., Sato, Y., Masaki, T., et al. (2016). Anomalous orange light-emitting $(\mathrm{Sr}, \mathrm{Ba})_{2} \mathrm{SiO}_{4}: \mathrm{Eu}^{2+}$ phosphors for warm white LEDs. ACS Appl. Mater. Interfaces 8, 11615-11620. doi: 10.1021 /acsami.6b02237

Wu, W.-L., Fang, M.-H., Zhou, W., Lesniewski, T., Mahlik, S., Grinberg, M., et al. (2017). High color rendering index of $\mathrm{Rb}_{2} \mathrm{GeF}_{6}: \mathrm{Mn}^{4+}$ for light-emitting diodes. Chem. Mater. 29, 935-939. doi: 10.1021/acs.chemmater.6b05244

Xi, L., Pan, Y., Zhu, M., Lian, H., and Lin, J. (2017). Room-temperature synthesis and optimized photoluminescence of a novel red phosphor $\mathrm{NaKSnF}_{6}: \mathrm{Mn}^{4+}$ for application in warm WLEDs. J. Mater. Chem. C 5, 9255-9263. doi: 10.1039/C7TC02996A

Ye, T., Li, S., Wu, X., Xu, M., Wei, X., Wang, K., et al. (2013). Sol-gel preparation of efficient red phosphor $\mathrm{Mg}_{2} \mathrm{TiO}_{4}: \mathrm{Mn}^{4+}$ and XAFS investigation on the substitution of $\mathrm{Mn}^{4+}$ for $\mathrm{Ti}^{4+}$. J. Mater. Chem. C 1, 4327-4333. doi: 10.1039/C3TC30553H

Zhang, S., Hu, Y., Duan, H., Fu, Y., and He, M. (2017). An efficient, broad-band red-emitting $\mathrm{Li}_{2} \mathrm{MgTi}_{3} \mathrm{O}_{8}: \mathrm{Mn}^{4+}$ phosphor for blue-converted white LEDs. J. Alloys Compd. 693, 315-325. doi: 10.1016/j.jallcom.2016.09.203

Zhou, Z., Zhou, N., Xia, M., Yokoyama, M., and Hintzen, H. T. (2016). Research progress and application prospects of transition metal $\mathrm{Mn}^{4+}$. activated luminescent materials. J. Mater. Chem. C 4, 9143-9161. doi: $10.1039 / \mathrm{c} 6 \mathrm{tc} 02496 \mathrm{c}$

Conflict of Interest Statement: The authors declare that the research was conducted in the absence of any commercial or financial relationships that could be construed as a potential conflict of interest.

Copyright $\odot 2018$ Kato, Takeda, Kobayashi, Kobayashi and Kakihana. This is an open-access article distributed under the terms of the Creative Commons Attribution License (CC BY). The use, distribution or reproduction in other forums is permitted, provided the original author(s) and the copyright owner(s) are credited and that the original publication in this journal is cited, in accordance with accepted academic practice. No use, distribution or reproduction is permitted which does not comply with these terms. 